\title{
Membranas de látex natural na herniorrafia diafragmática experimental em cães
}

[Natural latex membranes in experimental diaphragmatic hernioplasty in dogs]

\author{
M. Zimmermann ${ }^{1,3}$, A.G. Raiser ${ }^{2}$, F.V.A. Braga ${ }^{1,3}$, A.L.B. Trindade ${ }^{1,3}$, S.T.A. Lopes $^{2}$ \\ ${ }^{1}$ Aluna de pós-graduação - UFSM \\ 97105-900 - Santa Maria, RS \\ ${ }^{2}$ Departamento de Clínica de Pequenos Animais - UFSM - Santa Maria, RS \\ ${ }^{3}$ Bolsista do $\mathrm{CNPq}$
}

\begin{abstract}
RESUMO
Utilizaram-se membranas de látex para o reparo de defeitos diafragmáticos em 12 cães, distribuídos em três grupos: no G1 utilizou-se membrana comercial e no G2, membrana experimental. O G3 foi usado como controle. Foi feito um defeito retangular no músculo diafragma, com $4 \mathrm{~cm}$ de comprimento por $3 \mathrm{~cm}$ de largura, que nos grupos G1 e G2 foi substituído pelo implante da membrana de látex correspondente. Os animais foram avaliados por estudo radiográfico, hemograma, videocirurgia e análise histológica. Os resultados mostraram que a membrana de látex do grupo 2 foi eficiente na correção de defeito no diafragma, promovendo a reparação e neovascularização tecidual local, sem causar rejeição durante o período de avaliação.
\end{abstract}

Palavras-chave: cão, diafragma, implante, membrana de látex

\begin{abstract}
Latex membranes were experimentally used to repair diaphragmatic defects in 12 dogs, distributed in 3 groups. In group 1, a commercial membrane was used, and in group 2, an experimental membrane. Group 3, animals were used as control. A rectangular defect (4cm in length and $3 \mathrm{~cm}$ in width) was surgically performed in the diaphragm muscle, which was substituted, in group 1 and 2, by the implantation of corresponding latex membrane. The animals were evaluated by radiography, blood count, video-surgery, and histologic study. Results showed that the latex membrane of group 2, were efficient in the correction of the defect in the diaphragm, promoting the repairing and local neovascularization, without causing rejection during the evaluated period.
\end{abstract}

Keywords: dog, diaphragm, implantation, latex membranes

\section{INTRODUÇÃO}

A utilização de implantes como substituição parcial do diafragma justifica-se, principalmente, em casos de hérnia diafragmática (HD) que possibilita aos órgãos abdominais migrarem para a cavidade torácica. Essas hérnias podem ser congênitas ou traumáticas, em que o aumento abrupto na pressão intra-abdominal, que acompanha golpes forçados na parede abdominal, faz com que os pulmões se desinflem rapidamente (com a glote aberta), resultando em um gradiente de pressão pleuroperitoneal elevado. Isso provoca a ruptura do diafragma nos seus pontos mais frágeis, geralmente nas porções musculares (Fossum et al., 2002).

O tratamento cirúrgico de uma HD é mais arriscado quando for realizado em menos de $24 \mathrm{~h}$ ou um ano após a lesão. Deve-se retardar o reparo cirúrgico de uma hérnia diafragmática até que o paciente fique estabilizado (Fossum et al., 2002). Nesse período, podem ocorrer aderências, fibrose e retração do tecido. Segundo Johnson

Recebido em 1 de agosto de 2008

Aceito em 27 de novembro de 2008

E-mail: veterinariamarina@yahoo.com.br 
(1993), a formação de aderências maduras com maiores níveis de tecido fibrovascular organizado, inicia-se a partir da segunda semana após o traumatismo. Nesses casos, a correção cirúrgica pode ser dificultada, principalmente quando houver perda de tecido, e uma alternativa é a reparação com o uso de enxertos ou implantes.

Enxertos autólogos são bastante satisfatórios, como o uso de retalho pediculado do músculo grande dorsal, para reparo de defeito diafragmático (Oliveira et al., 2000), entretanto agridem a área doadora. Os implantes homólogos constituem uma alternativa atraente na cirurgia, mas as desvantagens são o risco de reações imunológicas e o potencial de transmissão de doenças infecciosas (Paccola et al., 2000). Mazzanti et al. (2001) utilizaram segmento de músculo diafragma como homoimplante, conservado em solução de açúcar $300 \%$ por 30 dias, sem a observação de rejeição. Implante com pericárdio bovino conservado em açúcar promoveu a restauração do defeito no diafragma sem causar evidências de infecção ou rejeição (Mazzanti et al., 2003). Entretanto, algumas desvantagens dessas técnicas são: necessidade de doador; meio conservante; conservação por 30 dias antes da utilização; possuir banco de implantes. Outrossim, implantes de malhas sintéticas têm alto custo, o que impede, algumas vezes, seu uso na medicina veterinária.

As características principais de um material sintético para uso como reforço em defeitos herniários são: não favorecer rejeição, ou reação de corpo estranho e não produzir reação de hipersensibilidade; não ser modificado fisicamente quando em contato com os tecidos; não produzir carcinogênese nem complicações; ser quimicamente inerte, facilmente manipulável; ser esterilizável; ser resistente ou participar da formação de tecido resistente; possuir baixo custo (Cumberland, 1952, citado por Sousa, 2005).

Há interesses no estudo da membrana de látex natural por esta apresentar propriedades indutoras da neovascularização e por auxiliar na reparação tecidual mais rápida. Obteve-se sucesso ao ser aplicada na herniorrafia perineal em um cão, permitindo fechamento do defeito no anel herniário, deixando uma base tecidual após sua remoção (Paulo et al., 2005b). Em bovinos com hérnia umbilical recidivante, a membrana de látex possibilitou a correção cirúrgica de caráter permanente (Rabelo et al., 2005). Esses resultados sugerem que a membrana de látex seja uma alternativa para corrigir defeitos no diafragma canino.
A videocirurgia na medicina veterinária é um procedimento cirúrgico com aplicação diagnóstica e terapêutica. Essa técnica tem inúmeras vantagens quando comparada a procedimentos tradicionais como: menor traumatismo cirúrgico; dor pósoperatória menos intensa; menor tempo de hospitalização; recuperação mais rápida do paciente; menor custo hospitalar (Malm, 2003). A avaliação pós-operatória experimental com uso deste procedimento é pertinente, haja vista que promove maior bem estar animal e diagnóstico preciso, possibilitando ainda a biopsia da região em estudo.

O objetivo deste estudo foi avaliar a eficiência de uma membrana de látex elaborada a baixo custo (comparada à outra já comercializada para outros fins) na reparação de defeito no diafragma de cão.

\section{MATERIAL E MÉTODOS}

Foram utilizadas 12 cadelas, sem raça definida, adultas, pesando de 8,0 a $12,0 \mathrm{~kg}$, hígidas. Os animais foram mantidos em recintos individuais, alimentados com ração comercial e água $a d$ libittum.

Foram constituídos três grupos experimentais, com quatro cadelas em cada: no grupo 1, utilizou-se membrana de látex comercial'; no grupo 2, membrana de látex experimental; no grupo 3, o controle, auferiu-se proveito do próprio segmento seccionado, suturado no defeito. A membrana utilizada no grupo 1 foi composta de látex centrifugado mais polilisina $0,1 \%$; a membrana de látex utilizada no grupo 2 foi desenvolvida com látex in natura (não centrifugado), água, na proporção de 2:3, em que foram adicionados, ainda, ácido fórmico e $8 \mathrm{ml}$ de mistura vulcanizante, composta de mercaptobenzotiazol (MBT), dietilditiocarbamato de zinco (ZDEC), óxido de zinco e enxofre. Para esterilização, foi submetida à autoclavagem por 15 minutos a $121^{\circ} \mathrm{C}$. Essa membrana já foi testada em experimentos prévios quanto à biocompatibilidade e resistência (Zimmermann et al., 2007).

Após jejum prévio de 12 horas e tricotomia ampla no tórax direito, os animais foram pré medicados com maleato de acepromazina $\left(0,1 \mathrm{mg} \mathrm{kg}^{-1}\right)$ e cloridrato de fentanila $\left(2,5 \mu \mathrm{g} \quad \mathrm{kg}^{-1}\right)$ via intramuscular e, após 15 minutos, foram induzidos com propofol $\left(2 \mathrm{mg} \mathrm{kg}^{-1}\right)$ intravenoso, sendo

${ }^{1}$ Biocure -- Pele Nova Biotecnologia S/A, Mato Grosso MS - Brasil. 
mantidos em plano anestésico com halotano, vaporizado e oxigênio. O ritmo e a freqüência cardíaca foram observados em monitor eletrocardiógrafo e a saturação de oxigênio foi avaliada em oxímetro com sensor posicionado na língua do paciente. Em cada animal, foram aplicados $30 \mathrm{mg} \mathrm{kg}^{-1}$ de cefalotina sódica IV, $30 \mathrm{~min}$ antes da cirurgia.

Todos os procedimentos cirúrgicos foram efetuados em bloco cirúrgico com rigoroso controle de assepsia. No trans-operatório, foi efetuada toracotomia intercostal, com acesso pelo oitavo espaço intercostal direito. Criou-se um defeito retangular no músculo diafragma, com $4 \mathrm{~cm}$ de comprimento por $3 \mathrm{~cm}$ de largura, que, nos grupos 1 e 2, foi substituído pelo implante de membrana de látex correspondente, fixado por sutura de Wolff, com fio monofilamentar de náilon $\mathrm{n}^{\circ} 3-0$, com sobreposição de bordas. No grupo controle, o segmento retangular do músculo diafragma foi removido e refixado por sutura seguindo o mesmo procedimento. A seguir, realizou-se toracorrafia, em sutura circuncostal com náilon monofilamentar 3-0. Os músculos intercostais, o grande dorsal e o tecido subcutâneo, foram ocluídos com poliglactina $910 \mathrm{n}^{\circ} 3-0$. A sutura cutânea foi feita com fio monofilamentar 3-0. A restituição da pressão negativa foi obtida com hiperinsuflação, antes do fechamento do último ponto da parede torácica, associada à drenagem por toracocentese do ar residual após o término da cirurgia.

A analgesia foi desenvolvida com tramadol via oral (BID, 2mg kg-1), por meio de bloqueio intercostal, sendo utilizada bupivacaina com vaso constritor $\left(1 \mathrm{mg} \mathrm{kg}^{-1}\right)$ no pós-operatório imediato e com uso de antiinflamatório não esteroidal, flunixina meglunina (SID, $1,1 \mathrm{mg} \mathrm{kg}^{-1}$ ), por via subcutânea durante três dias. Além disso, cumpriram-se higienização e bandagem levemente compressivas. A retirada dos pontos cutâneos foi efetuada aos sete dias de pósoperatório.

A avaliação clínica foi obtida mediante inspeção diária da ferida cirúrgica, do padrão respiratório e da monitorização da dor nos 10 dias de pósoperatório, com base em um escore de intensidade, elaborados especificamente para este experimento (Tab. 1). Foram executados hemogramas no dia zero, antes da intervenção cirúrgica, e aos 15 e 30 dias de pós-operatório. A avaliação estatística desses dados foi obtida por meio do teste Tukey-Kramer $(\mathrm{P}<0,05)$, com auxílio do programa estatístico GraphPad Prism 4.00 version $^{2}$. Como exame complementar, realizou-se ainda estudo radiográfico aos 20 dias de pós-operatório.

A avaliação macroscópica e a biopsia da região do defeito diafragmático foram realizadas por meio de vídeocirurgia aos 30 dias de pósoperatório. Para isso, o instrumental foi desinfectado com glutaraldeído a $2 \%$, por 40 minutos e depois lavado com solução salina. Para o acesso laparoscópico, foi feita incisão de pele com bisturi e punção da cavidade abdominal com agulha de Veress, promoveu-se a introdução de três trocartes, sendo o primeiro da câmera e os demais para utilização do instrumental cirúrgico. O portal de $10 \mathrm{~mm}$ foi colocado na cicatriz umbilical por onde teve acesso a óptica, outro portal de $10 \mathrm{~mm}$ foi posicionado no lado esquerdo do paciente, ligeiramente caudal à $13^{\mathrm{a}}$ costela e um de $5 \mathrm{~mm}$ contra-lateral a este. A biopsia foi obtida da borda do defeito diafragmático na sua face abdominal, com aproximadamente $0,5 \mathrm{~cm}$ de comprimento. Após sua coleta, cada amostra foi imediatamente acondicionada em frasco contendo formaldeido a $10 \%$ tamponado e encaminhada para processamento e estudo histológico. Para análise morfológica com estudo em microscopia óptica, cada amostras foi incluída em parafina e corada pela eosina-hematoxilina. Procedeu-se também a toracoscopia, utilizando-se um portal de $10 \mathrm{~mm}$ no terço médio do sétimo espaço intercostal direito, pelo qual penetrou a óptica. Após inspeção torácica, o fechamento da ferida de acesso foi obtido com fio poligalactina 910 e a pele suturada com poliamida 3-0, ambos em padrão interrompido simples.

O experimento foi aprovado pelo Comitê de Ética da Universidade Federal de Santa Maria (processo 23081.008621/2006-88) e, ao final, todos os animais utilizados foram castrados e doados.

${ }^{2}$ GraphPad Software Inc. - San Diego, EUA. 
Tabela 1. Critérios para a avaliação da dor aguda no pós-operatório de cães submetidos à toracotomia, laparotomia e videocirurgia

\begin{tabular}{|c|c|c|c|}
\hline \multirow{2}{*}{ Parâmetro avaliado } & \multicolumn{3}{|c|}{ Escore de intensidade } \\
\hline & 0 & 1 & 2 \\
\hline Batimentos cardíacos & 70 a 120 - Normal & Taquicardia & \\
\hline Movimentos respiratórios & 10 a 20 - Normal & Taquipéia & Padrão abdominal \\
\hline Temperatura & Normal & Hipertermia & \\
\hline & 37,5 a $39,0^{\circ} \mathrm{C}$ & $>39,0^{\circ} \mathrm{C}$ & \\
\hline Salivação & $\begin{array}{c}\text { Normal - mucosa úmida e } \\
\text { brilhante }\end{array}$ & $\begin{array}{l}\text { Aumentada - } \\
\text { excesso de secreção }\end{array}$ & \\
\hline Pupilas (luz ambiente) & Miose & Midríase & \\
\hline Estado mental & Dócil & Alerta/medo & Agressivo \\
\hline Vocalização & Ausência & Presença & \\
\hline Postura e atitude & Ereta e alegre & $\begin{array}{l}\text { Arqueado ou } \\
\text { deitado e triste }\end{array}$ & \\
\hline Resposta à manipulação & Não reage & $\begin{array}{c}\text { Reação leve, } \\
\text { esquiva-se }\end{array}$ & $\begin{array}{l}\text { Reação brusca, } \\
\text { morde }\end{array}$ \\
\hline Locomoção & Normal & Com dificuldade & Não movimenta \\
\hline Apetite & Normorexia & Hiporexia & Anorexia \\
\hline Ganho peso & Igual ou ganho & Perda & \\
\hline Micção & Normal & $\begin{array}{l}\text { Com dificuldade, } \\
\text { pouco e freqüente }\end{array}$ & Não urina \\
\hline Defecação & Normal & Com dificuldade & Não defeca \\
\hline
\end{tabular}

Presença de dor verificada pela soma dos escores:

0 a 4 - ausência de dor.

5 a 6 - dor moderada.

$\geq 7$ - dor intensa.

\section{RESULTADOS E DISCUSSÃO}

Todos os animais apresentaram boa evolução clínica, entretanto, houve formação de edema ao redor da ferida operatória, em 10 cadelas, durante os dois primeiros dias de pós-operatório e deiscência da sutura de pele em duas cadelas, atribuídas à lambedura do local. Nesses casos optou-se pela cicatrização por segunda intenção.

No grupo 1, em que foi utilizada a membrana de látex em uso comercial, os resultados na vídeocirurgia evidenciaram hérnia diafragmática nos quatro animais estudados, três deles com comprovação radiográfica aos 20 dias após implantação, em que se verificou a presença de parte do figado, confirmada por técnica contrastada, que segundo Raiser (1993) e Mazzanti (2003), é o exame mais eficiente para diagnosticar hérnia diafragmática.

Um dos três animais do grupo 1 apresentou dispnéia e sons cardíacos abafados, aos 20 dias de pós-operatório, com imagem sugestiva de hidrotórax pelo exame radiográfico. Após a toracocentese, foram drenados $800 \mathrm{ml}$ de líquido serossangüinolento, no qual, após análise laboratorial, não se constatou contaminação bacteriana. $\mathrm{O}$ animal permaneceu com dreno torácico para retiradas diárias de líquido, seguindo orientação de Ludwig (2000), que cita a necessidade de drenagens contínuas quando houver rápido acúmulo de ar ou líquido no espaço pleural. Segundo esse autor, o dreno deve permanecer enquanto houver produção maior que $2 \mathrm{ml} \mathrm{kg}^{-1} \mathrm{dia}^{-1}$. Neste animal, foram drenados ainda $200 \mathrm{ml}$ de líquido torácico, duas vezes ao dia, com a permanência do dreno por 10 dias, até a correção cirúrgica da hérnia. O fígado, presente no conteúdo herniário, estava congesto e sob constrição, sendo responsável pela efusão. Profilaxia antibiótica com cefalotina (30 $\left.\mathrm{mg} \mathrm{kg}^{-1}\right)$ foi instituída até a retirada do dreno, já que este estava em contato com meio externo e poderia carrear bactérias para a cavidade torácica.

No quarto animal do grupo 1, não foi possível o diagnóstico por estudo radiográfico, o conteúdo herniado era o omento maior, que estava aderido ao diafragma ocluindo o local de ruptura, sem alterações clínicas. Essa condição só foi evidenciada por videolaparoscopia. 
Aos 25 dias de pós-operatório, um animal veio a óbito e, pela necropsia comprovou-se a migração para a cavidade torácica do baço e do intestino além do estômago que sofreu dilatação aguda. Neste grupo, ocorreu ruptura da membrana de látex em todos os animais, permanecendo os pontos de sutura nas bordas do defeito. Isto se deve ao fato da membrana comercial possuir espessura de $100 \mu \mathrm{m}$, enquanto a membrana utilizada no grupo 2 possuía $1,4 \mathrm{~mm}$ de espessura, em média. Em estudo realizado por Zimmermann et al. (2006), em que testes de tração foram realizados com amostras de diferentes membranas de látex, incluindo as membranas usadas nos grupos 1 e 2, foi constatado que a espessura do material influencia diretamente na sua resistência. A amostra do grupo 1 não resistiu nem ao peso mínimo do aparelho, de $340 \mathrm{~g}$, enquanto a amostra do grupo 2 , resistiu a $18,75 \mathrm{~kg}$.

Nos animais do grupo 2, o estudo radiográfico não evidenciou alterações sugestivas de hérnia diafragmática. Na avaliação por laparoscopia, constatou-se que a membrana estava íntegra e fixa ao diafragma. Em três animais, a membrana estava coberta com tecido de granulação, com aderências ao omento em uma cadela, e ao fígado nas outras duas. Na quarta cadela, o tecido de granulação não cobria totalmente a membrana, sendo possível observá-la por acesso abdominal e constatando-se a ausência de aderências. Não houve evidências macroscópicas de inflamação, presença de líquido ou alterações em vísceras abdominais próximas ao diafragma. $\mathrm{Na}$ avaliação por toracoscopia, verificou-se a formação de tecido de granulação sobre as membranas, que era parcial em dois animais e nos outros dois recobria inclusive o fio de sutura.

Em dois animais, houve aderências do pulmão ao local da ferida, sem a presença de líquido e reação inflamatória no tórax. Aderências do fígado e omento ao diafragma foram achados comuns nos estudos de Mazzanti et al. (2001; 2003), que atribuíram-nas à proximidade do defeito com o fígado $\mathrm{e}$ ao sangramento observado nas bordas do defeito com conseqüente deposição de fibrina, o que também foi observado neste experimento. Oliveira et al. (2000) constataram aderências, quando utilizaram retalho pediculado do músculo grande dorsal, tanto com o fígado e o omento, quanto com o pulmão, no tórax; a reação foi atribuída ao fio de seda utilizado na rafia, além da manipulação e da ausência de uma superfície serosa.

Acredita-se que alguns implantes utilizados, tais como, pericárdio bovino (Mazzanti et al., 2003), músculo diafragma homólogo (Mazzanti et al., 2001) e retalho pediculado do músculo grande dorsal (Oliveira et al., 2000) predisponham a formação de aderências. O mesmo não ocorre com o implante de membrana de látex, pois é o tecido de granulação que se adere com facilidade aos tecidos vizinhos. Este resultado está de acordo com Sousa (2005), que não observou incorporação de biomembranas de látex aos tecidos vizinhos nem indução de fibrose na correção de inguinoplastias. Para Pinho et al. (2004), a membrana de látex, quando usada na reparação conjuntival de coelho, não se aderiu ao tecido subjacente, permanecendo presa pelos pontos de sutura, permitindo epitelização.

Os resultados observados nos animais do grupo 3 foram semelhantes aos do grupo 2 com relação ao exame radiográfico. A avaliação por toracoscopia e laparoscopia não evidenciaram alterações, hérnias ou inflamação. Neste grupo, devido à coaptação das bordas do defeito com o retalho autólogo do diafragma, foram observadas duas aderências, que ocorreram do pulmão ao local de sutura no diafragma, em duas cadelas. Um animal deste grupo veio a óbito no pósoperatório imediato à vídeocirurgia, mas os achados da necropsia não relacionaram nenhuma alteração compatível com o experimento. A causa do óbito relacionou-se ao procedimento anestésico.

O acesso para implantação das membranas, realizado pelo oitavo espaço intercostal direito, conforme descrito por Raiser (1993), possibilitou rápida e fácil intervenção cirúrgica. $\mathrm{O}$ ponto de Wolff com sobreposição de bordas proporcionou boa vedação entre o implante de látex e o diafragma. Nos animais com ruptura da membrana (grupo 1) justificou-se pela espessura desta, já que a sutura permaneceu íntegra neste e nos demais grupos. Este tipo de sutura também foi eficaz quando empregado nos estudos de Oliveira et al. (2000) e de Mazzanti et al. (2001). A escolha do fio de sutura, poliamida 3-0, devese ao fato de ser um material não absorvível, sintético, monofilamentar, resistente e caracterizado por induzir mínima reação tecidual 
(Fossum, 2002), estando de acordo com Mazzanti et al. (2003) e com (Raiser, 1993) que utilizaram esse mesmo fio de sutura, para corrigir defeito no diafragma de cão.

O uso da laparoscopia e da toracoscopia, conforme descrito por Beck et al. (2004a,b), na avaliação e diagnóstico das hérnias diafragmáticas, possibilitou a avaliação do implante de forma pouco invasiva. Em três animais do grupo 1 , foi necessária a conversão para cirurgia aberta, para a redução da hérnia diafragmática, pois parte do fígado encontrava-se encarcerado, congesto e friável, dificultando sua redução por vídeocirurgia, requerendo uma abordagem mais rápida pelo cirurgião. Esta é uma complicação que interfere no êxito da redução pela técnica de videolaparoscopia descrita por de Beck et al. (2004b).

Nenhum animal do experimento demonstrou características de dor, quando avaliados pelo escore de 0 a 4 (Tab. 1). Isto se deve ao fato de ter sido utilizada analgesia preemptiva. Outro importante fator que possibilitou adequada analgesia pós-operatória consistiu no uso de anestesia local. Glowaski (2002) afirma que essa modalidade promove maior conforto e cooperação do paciente durante procedimentos dolorosos e indica o uso de bloqueio intercostal após toracotomias. Segundo esse autor, a bupivacaina, que promove analgesia de seis horas, se associada à epinefrina como vasoconstritor, tem seu efeito prolongado, diminuindo a dose necessária.

Os resultados dos hemogramas evidenciaram diferenças na contagem dos linfócitos aos 30 dias de pós-operatório. No grupo 1, essa contagem foi estatisticamente diferente do grupo-controle $(\mathrm{P}<0,05)$. O grupo 2 não diferiu dos outros tratamentos. Isso significa que a membrana comercial utilizada no grupo 1 induziu maior resposta antigênica. Segundo Meyer e Harvey (1998), os linfócitos proliferam em resposta a uma estimulação antigênica. A linfocitose é rara em cães mas pode ocorrer em resposta a estimulação antigênica persistente, infecções crônicas ou reações inflamatórias crônicas (Schultze, 2000; Meyer e Harvey, 1998). No presente experimento, a membrana de látex estava estimulando esta reação, pois se caracterizou como corpo estranho e induziu a resposta antigênica do organismo, durante o tempo que nele permaneceu.

A microscopia ótica revelou corte longitudinal de músculo estriado, sobre o qual se observava extensa proliferação de tecido fibrovascular (TFV) frouxo, em sete animais com proliferação de TFV denso, e em cinco com extensas áreas densamente colageinizadas, com quantidade moderada de infiltrado misto, predominantemente mononuclear. A espessura da proliferação do tecido foi equivalente à largura da biopsia. Havia neovascularização, reparação tecidual e, na maioria das lâminas, presença de células musculares gigantes. Essas alterações fazem parte da cicatrização tecidual em sua fase de reparo, em que há síntese de colágeno, orientação das fibras e dos capilares e diminuição do infiltrado inflamatório (Fossum, 2002).

Não foram encontrados, na literatura revisada, trabalhos que citem a utilização da membrana de látex como substituto parcial de diafragma em nenhuma espécie. A neovascularização e a reparação tecidual com uso de látex foram descritas por Paulo et al. (2004a,b), na herniorrafia perineal de um cão e na reconstrução da parede abdominal de ratos, respectivamente. Rabelo et al. (2005) citaram o uso desse material na correção de hérnias umbilicais de bovinos. Essas pesquisas, além daquelas com reconstrução da membrana timpânica (Oliveira et al., 2003) e de úlceras isquêmicas (Frade, 2003) em seres humanos; e das relacionadas à reparação esofágica e da parede abdominal de cães (Mrué, 2000), indicam que a membrana induz a formação de uma matriz fibrovascular capaz de substituir o tecido original onde for implantada.

A membrana testada no grupo 1 mostrou-se frágil e não sustentou a tensão no diafragma, possibilitando a formação de hérnia e a indução de antigenicidade. Já a membrana implantada nos animais do grupo 2 (Fig. 1), foi satisfatória na reparação do diafragma de cães, sendo de fácil manipulação por ser mais espessa e rígida. Ademais, não induziu reação antigênica e promoveu a formação de tecido de granulação com capacidade de dar sustentação e manter a integridade da cavidade torácica, possibilitando a função respiratória e mantendo o bem estar animal, semelhante ao grupo-controle. 


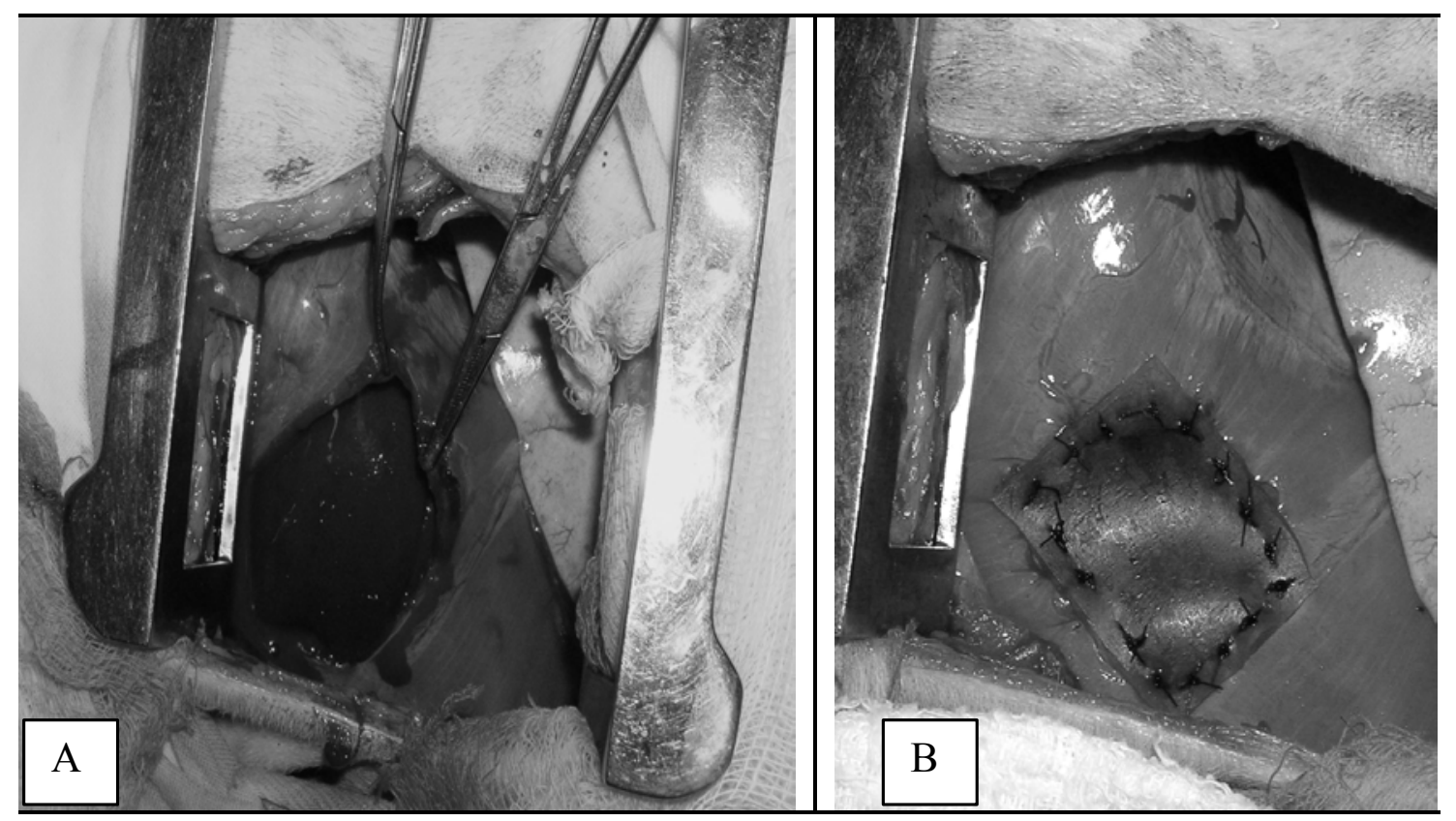

Figura 1. Animal do grupo 2, em que se evidenciam: A) o aspecto do defeito realizado no diafragma; B) membrana de látex natural após ser suturada sobre o defeito no diafragma.

\section{CONCLUSÃO}

A membrana de látex, experimental, usada no grupo 2, pode ser utilizada como substituto parcial do diafragma em cães, pois promove neovascularização e reparação tecidual e mantém a função do diafragma.

\section{REFERÊNCIAS BIBLIOGRÁFICAS}

BECK, C.A.C.; PIPPI, N.L.; BRUN, M.V. et al. Laparoscopia nas hérnias diafragmáticas: estudo experimental em cães. Cienc. Rural, v.34, p.1849$1855,2004 \mathrm{a}$.

BECK, C.A.C.; PIPPI, N.L.; BRUN, M.V. et al. Toracoscopia nas hérnias diafragmáticas: estudo experimental em cães. Cienc. Rural, v.34, p.1857$1863,2004 b$.

CUMBERLAND, V.H. A preliminary report on the use of prefabricated nylon weave in the repair of ventral hernia. Med. J. Aust., v.1, p.143-144, 1952.

FRADE, C.A.M. Úlcera de perna: caracterização clínica e perfil imunohistopatologico da cicatrização na presença da biomembrana de látex natural da seringueira. 2003. 164f. Tese (Doutorado) - Faculdade de Medicina de Ribeirão Preto, Universidade de São Paulo, Ribeirão Preto.

FOSSUM, T.W.; HEDLUND, C.S.; HULSE, D.A. et al. Cirurgia do sistema respiratório inferior: cavidade pleural e diafragma. In: . Cirurgia de pequenos animais. São Paulo: Roca, 2002. p.752-785.

GLOWASKI, M.M. Analgesia in critical care. Vet. Clin. N. Am.: Small Anim. Pract., v.32, p.1127-1144, 2002.

JOHNSON, K.A. Diaphragmatic, pericardial, and hiatal hernia. In: SLATTER, D. Textbook of small animal surgery. 2.ed. Philadelphia: Saunders, 1993. v.1, p.455-470.

LUDWIG, L.L. Surgical emergencies of the respiratory system. Vet. Clin. N. Am.: Small Anim. Pract., v.30, p.531-553, 2000.

MALM, C. Ovário-histerectomia: estudo experimental comparativo entre as abordagens laparoscópicas e aberta na espécie canina. 2003. 190f. Tese (Doutorado) - Escola de Veterinária, Universidade Federal de Minas Gerais, Belo Horizonte.

MAZZANTI, A.; RAISER, A.G.; PIPPI, N.L. et al. Hernioplastia diafragmática em um cão com pericárdio bovino conservado em solução supersaturada de açúcar. Arq. Bras. Med. Vet. Zootec., v.55, p.677-684, 2003.

MAZZANTI, A.; PIPPI, N.L.; RAISER, A.G. et al. Músculo diafragma homólogo conservado em solução supersaturada de açúcar para reparação de grande defeito no diafragma de cão. Cienc. Rural, v.31, p.277-283, 2001. 
MEYER, J.D.; HARVEY, W.J. Evaluation of leukocytic disorders. In: _. Veterinary laboratory medicine. Philadelphia: Saunders, 1998. p.83-109.

MRUÉ, F. Neoformação tecidual induzida por biomembrana de látex natural com polilisina. Aplicabilidade em neoformação esofágica e da parede abdominal. Estudo experimental em cães. 2000. 112f. Tese (Doutorado) -. Faculdade de Medicina de Ribeirão Preto, Universidade de São Paulo, Ribeirão Preto.

OLIVEIRA, A.A.J.; HYPPOLITO, M.A.; MRUÉ, F. et al. Miringoplastia com a utilização de um novo material biosintético. Rev. Bras. Otorrinolaringol., v.69, p.649-655, 2003.

OLIVEIRA, O.L.; PIPPI, N.L.; GRAÇA, D.L. et al. Retalho pediculado do músculo grande dorsal para reparo de defeito diafragmático experimental em cães. Cienc. Rural, v.30, p.1005-1009, 2000.

PACCOLA, C.A.J.; KFURI JUNIOR, M.; CUNHA, P.S.A. et al. Reconstrução do ligamento cruzado anterior com ligamento patelar. Análise comparativa do ligamento autólogo versus homólogo. Acta Ortop. Bras., v.8, p.202-208, 2000.

PAULO, N.M.; LIMA, F.G.; SIQUEIRA JUNIOR, J.T. et al. Membrana de látex da seringueira (Hevea brasiliensis), com e sem polilisina a $0,1 \%$ e tela de marlex na reconstrução de defeitos iatrogênicos da parede abdominal de ratos. Acta Sci., v.20, p.305, $2005 \mathrm{a}$.

PAULO, N.M.; SILVA, M.A.M.; CONCEIÇÃO, M. et al. Biomembrana de látex natural (Hevea brasiliensis) com polilisina a $0,1 \%$ para herniorrafia perineal em um cão. Acta Scientiae, v.33, p.79-82, 2005 b.
PINHO, E.C.C.M.; SOUSA, S.J.F.; SCHAUD, F. et al. Uso experimental da biomembrana de látex na reconstrução conjuntival. Arq. Bras. Oftalmol., v.67, p.27-32, 2004.

RABELO, E.R.; SANT'ANA, F.J.F.; PAULO, N.M. et al. Emprego do compósito látex, polimida e polilisina a $01 \%$ na correção cirúrgica de hérnias umbilicais recidivantes em bovinos leiteiros. Acta Sci., v.33, p.169-175, 2005.

RAISER, A.G. Hérnias em cães e gatos - análise de 188 casos e proposição de técnica de herniorrafia para ruptura costal do diafragma. 1993. 108f. Tese (Tese para acesso à classe de professor titular) Faculdade de Medicina Veterinária, Universidade Federal de Santa Maria, Santa Maria.

SADER, S.L.; COUTINHO NETTO, J.; BARBIERI NETO, J. et al. Substituição parcial do pericárdio de cães por membrana de látex natural. Rev. Bras. Cir. Cardiovasc., v.15, p.338-344, 2000.

SCHULTZE, E.A. Interpretation of canine leukocyte responses. In: FELDMAN, B.F.; ZINKL, J.G.; JAIN, N.C. et al. Schalm's veterinary hematology. Baltimore: Lippincott Williams \& Wilkins, 2000. p.366-381.

SOUSA, H.L. Avaliação morfológica da utilização da prótese de látex na inguinoplastia videolaparoscópica. Estudo experimental em cães. 2005. 69f. Tese (Doutorado) - Faculdade de Medicina de Ribeirão Preto, Universidade de São Paulo, Ribeirão Preto.

ZIMMERMANN, M.; RAISER, A.G.; BARBOSA, A.L.T. et al. Teste de biocompatibilidade e resistência de membranas de látex em cães. Cienc. Rural, v.37, p.1719-1723, 2007. 